\title{
Women in geosciences within the Italian University system in the last 20 years
}

\author{
Claudia Agnini ${ }^{1}$, Martha G. Pamato ${ }^{1}$, Gabriella Salviulo ${ }^{1}$, Kim A. Barchi ${ }^{2}$, and Fabrizio Nestola ${ }^{1,3}$ \\ ${ }^{1}$ Dipartimento di Geoscienze, Università degli Studi di Padova, Via G. Gradenigo 6, 35131 Padova, Italy \\ ${ }^{2}$ Centro Linguistico di Ateneo, Università degli Studi di Padova, Via Venezia 16, 35131 Padova, Italy \\ ${ }^{3}$ Geoscience Institute, Goethe University Frankfurt, Altenhoeferalle 1, 60438 Frankfurt am Main, Germany
}

Correspondence: Claudia Agnini (claudia.agnini@unipd.it)

Received: 7 December 2019 - Revised: 24 April 2020 - Accepted: 29 June 2020 - Published: 7 August 2020

\begin{abstract}
This work aims at providing an updated scenario on the underrepresentation of women in the Italian university system in the area of geosciences in the last two decades. The retrieved official data on permanent full and associate professors in the 19-years considered highlight some positive trends: an increase in the number of female full professors from $9.0 \%$ to $18.5 \%$ and in female associate professors from $23.6 \%$ to $28.9 \%$. However, although the number of female full professors almost doubled in this period, such increase still represents an excessively slow trend. Slightly better is the trend related to associate professors. The picture portrayed for non-permanent researchers, called RTD-b, as introduced by the Italian Law no. 240/2010 (essentially tenuretrack associate professor position), instead raises strong concerns for the future seen that the female percentage is just $26 \%$, thus exhibiting a significant gender imbalance. This is even more significant if we consider that the student population in geosciences shows a gender imbalance of about $37 \%$, no gender gap at $\mathrm{PhD}$ level and a relatively high Glass Ceiling Index (GCI) during the career progression of women.

An analysis of the geographical distribution of female researchers in geosciences has evidenced that, although the percentages of women are comparable, the GCI calculated in Southern Italy has been alarmingly high in the last 2-3 years and is divergent from the decrease observed in Northern and Central Italy.

The work also analyses the gender balance over different areas of geosciences, showing that in Paleontology and $\mathrm{Pa}$ leoecology the gap is inverted with more female than male professors, both at full and associate professor level, whereas the gap is almost closed in Mineralogy for associate profes-
\end{abstract}

sors, far though from being balanced for full professors. All remaining geological disciplines suffer a gender imbalance.

Further analysis carried out in this work unveils that the number of female full professor is low $(<10 \%)$ both at national and regional level in the 2000-2009 decade, consistent with a GCI higher than 2.5-3. From 2010 to 2013, likely in response to the Italian Law no. 240 of 2010, an important progressive increase, associated with a decrease of GCI, is visible. However, from 2014 to 2019 the percentage remains constant $(\sim 20 \%)$ with the exception of Southern Italy, which displays a return to lower values $(<15 \%)$.

Finally, an international comparison with countries like Germany and the USA definitively indicates that the Italian university system is more equal in terms of gender balance.

Even if some significant and positive steps have been carried out in the Italian university system, still much effort is required to fight a general and crucial problem which is the gender balance issue. Results could be achieved promoting work-life balance policies that better reconcile family and work, stimulating a reorganization of the work system still currently set on the male model but, and more importantly, changing the prevailing patriarchal mentality.

The Italian university system has already a great example to follow: the zero-pay gap. This is possibly the only system worldwide where male and female professors earn the same identical salary, compared to the salary gap of between $15 \%$ and $30 \%$ of countries richer than Italy, and must be the target to reach, in the near future, for gender balance. 


\section{Introduction}

The underrepresentation of women in academia, the socalled gender gap, is a well-known, long-lasting feature among global university employers, yet some disciplines seem to emphasize the differences rather than try to reach gender equality. In particular women are underrepresented in higher positions, a phenomenon usually referred to as the "leaky pipeline". Many studies have focused on this issue trying to understand the reasons why the percentage of women among associate and full professors is lower than that of men (Filandri and Pasqua (2019) and references herein reported).

In geosciences, as well as in other hard sciences (i.e. Science, Technology, Engineering and Mathematics, known as STEM), most of the permanent positions are traditionally occupied by men, while women still represent a minority (e.g., Burke and Mattis, 2007; Ceci et al., 2009; Barone, 2011; Ceci and Williams, 2011; Macarie and Moldovan, 2015; Cheryan et al., 2017; EIGE, 2017b; European Commission, 2019; Roberto et al., 2020).

The out-dated stereotype of the typical geologist is, in fact, that of a man wearing hiking boots, carrying a heavy backpack with all the different field tools needed, trying to solve fundamental geological problems. Needless to say, we have come a long way from those times and, even if the contribution of the geologist is primarily related to the field, a number of new geological disciplines have developed in these last decades, revolutionising the traditional idea of a geologist (e.g., Broome, 2005).

With reference to the Italian scenario, furthermore, other aspects must be considered. First of all, in 2010 the Italian Law no. 240/2010 was implemented, while in 2013 the National Scientific Abilitation (ASN) system was introduced, profoundly changing the Italian university system. However, the question remains if such implementations have actually improved the recruitment policies and reduced the gender imbalance (e.g., Pautasso, 2015; Filandri and Pasqua, 2019).

Recently, Filandri and Pasqua (2019) ruled out the hypothesis that, at least in Italy, the difficulty in carrier advancements for women is related to lower productivity in terms of publications and/or women's reluctance to apply for promotions. This in turn suggests that the low presence of women in academia is not related to objective reasons but rather to gender inequality.

A deeper insight may be achieved thanks to the collection and analysis of quantitative data on the percentages of male and female Italian geoscientists, at different stages of their career. Three snapshots taken in 2001, 2009 and 2019 allow a better understanding of the changes over the last two decades, but, when necessary, the annual record was used granting the chance to comment on the step by step progression as well as possible near-future prospects.

Overall, the gender balance in the Italian university system in geosciences shows some positive trends when comparing the official data from the Italian Ministry of Educa- tion, University and Research (hereafter MIUR) collected between the end of 2001 and October 2019. However, improvements are still significantly needed, especially when the highest levels of "power" in terms of positions (i.e. full and associate professors) are considered as the GCI clearly displays higher values both with respect to the overall Italian system (Roberto et al., 2020) and the European scenario (European Commission, 2019). Glass ceiling represents an intangible barrier within a hierarchy that prevents women or minorities from obtaining upper-level positions; in this specific case, GCI is an estimation of the difficulty of women to reach top academic positions (European Commission, 2019). The present work is a contribution to the special issue "Diversity and Equality in the Geosciences" of the Advances in Geosciences journal, aiming at presenting the trends of women in geosciences within Italian universities, and at providing an updated picture of the Italian situation in comparison to that of other European and North American countries.

\section{Materials and methods}

In order to fully understand and interpret the official data, it is crucial, for the purpose of this work, to provide a clear scenario of how the Italian university system works and, in turn, the geosciences niche. The Italian university system is subdivided in 14 different scientific areas, as specified in the Italian Ministerial Decree of 4 October 2000. The socalled Area 04 (Earth sciences) includes all the geosciences that are further classified in 12 different areas called "Settori Scientifico-Disciplinari" (SSD - Scientific Disciplinary Sectors: academic disciplines for university research and teaching) listed as follows:

- GEO/01 Paleontology and paleoecology;

- GEO/02 Stratigraphic and Sedimentary Geology;

- GEO/03 Structural Geology;

- GEO/04 Physical Geography and Geomorphology;

- GEO/05 Applied Geology;

- GEO/06 Mineralogy;

- GEO/07 Petrology and Petrography;

- GEO/08 Geochemistry and Volcanology;

- GEO/09 Mining Resources, Mineralogic and Petrographic Applications for the Environmental and for Cultural Heritage;

- GEO/10 Solid Earth Geophysics;

- GEO/11 Applied Geophysics;

- GEO/12 Oceanography and physics of the Atmosphere. 
For the purpose of this work, the number of female full professors and associate professors at the end of 2001 (December), the end of 2009 (again December) and at October 2019 were analysed, providing an overview of the scenario over almost 20 years. Researcher positions were not discussed for four main reasons: (1) like most university systems around the world, professors usually have decision-making powers, both on political and scientific aspects (in terms of future strategies); (2) in the Italian system, full and associate professors have permanent employment positions, generally until their retirement age, and this ensures a more reliable comparison; (3) the Italian system, as per Italian Law no. 240 of 2010, introduced, in addition to the positions of full and associate professor, two types of research positions: they are both 3-years non-permanent positions, called type-A and type-B research contracts. In specific, the contract regarding type-A researchers ends at the end of the third year; while type-B researchers, assuming a satisfying performance, will be employed as associate professors by the university at the end of their research contract; (4) for purpose of comparison with other university systems, full and associate professor positions are similar in terms of teaching and administrative duties, thus allowing a reliable comparison.

The present work will therefore portray the evolution over the last 20-years and, at the same time, highlight how female professors are distributed within different geological (GEO) scientific SSDs and how the geography (i.e. Northern versus Central versus Southern Italy) may have influenced the total number of female professors. Finally, where possible (i.e. depending on the availability of official data), a comparison between the Italian and other international systems will be conducted.

\section{Females in geosciences in the Italian university systems}

In Italy, a typical academic career in geosciences is usually preceded by the acquisition of a master (MSc) followed by a doctoral $(\mathrm{PhD})$ degree and possibly a number of postdoctoral fellowships. To compare gender career paths, a scissor diagram, showing the percentages of male vs. female, is displayed in Fig. 1.

The percentage of female and male MSc students in geosciences in Italy, monitored from 2008 to 2018 , is relatively constant and varies between $35 \%-40 \%$ and $60 \%-65 \%$, respectively, consistent with the high percentages of males usually observed in STEM disciplines (Alma Laurea, 2019). At $\mathrm{PhD}$ level instead, there is an unexpected gender equality (49.4\% female in 2012 and $51.3 \%$ in 2014). This anomalous increase is difficult to explain, although it is commonly accepted that females are much more efficient than males in their curriculum studiorum (EUROSTAT, 2019; Fig. 1).

In order to compare the gender balance between Italian and European $\mathrm{PhD}$ students in all disciplines, a dataset show-

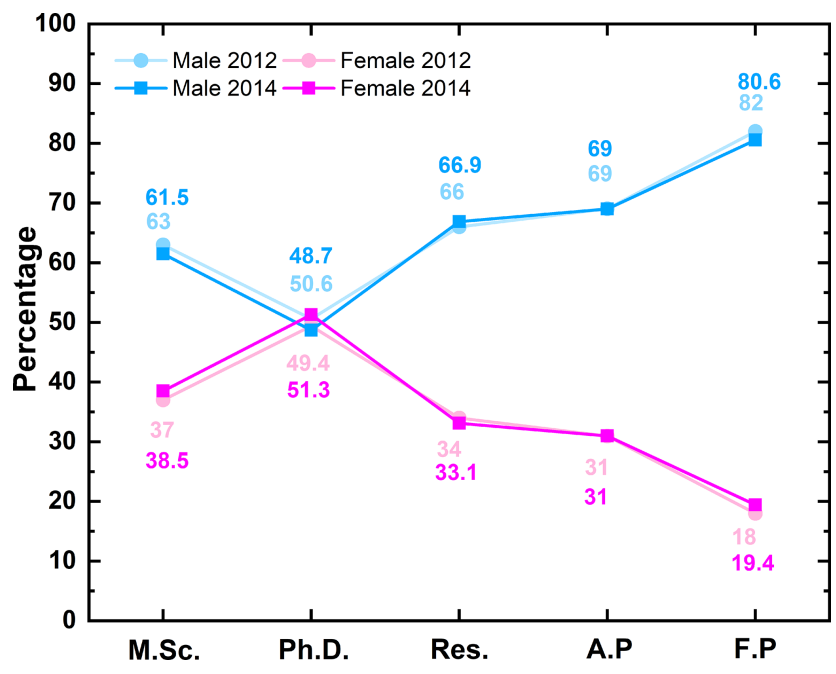

Figure 1. Proportion (\%) of male and female in a typical academic career in a two time-windows: 2012 and 2014. Scissor graph showing the percentages of female and male MSc graduate (data source: Alma Laurea, 2019, https://www.almalaurea.it/, last access: 31 October 2019) and PhD (data source: ISTAT, 2019, https://www.istat. it/, last access: 31 October 2019) students in geosciences as well as the proportion of women and men in the Italian academic staff (data source: MIUR, 2019, https://cercauniversita.cineca.it/php5/docenti/ cerca.php, last access: 31 October 2019).

ing the percentages of female students was collected for the year 2016 (Table 1, Fig. 2; European Commission, 2019). Additional data (from 2012 and 2014) available for Italian $\mathrm{PhD}$ students are also shown. All percentages display a substantial gender equality at $\mathrm{PhD}$ level (Figs. 1 and 2). It is noteworthy that, although the regulation of the Italian doctoral education substantially changed after the introduction of the Italian Ministerial Decree no. 345/2013, the overall trend does not appear to have been substantially modified. In fact, in 2016, the percentage of female Italian PhD students was 50.76 thus perfectly balanced (EUROSTAT, 2019). In 2014 and 2012, the percentages were 47.4 and 46.7, respectively, confirming a substantial gender equality. If compared with other European countries, these values are consistent with the general average of $47.8 \%$ female PhDs (Table 1; Fig. 2).

However, this balanced scenario changes when data available for academic staff are considered for the same time windows (i.e. 2012 and 2014). In fact, the number of females drastically decreases to $30 \%$ for researchers and associate professors, and collapses to $<20 \%$ for full professors, the so-called leaky pipeline (Fig. 1). This is in perfect agreement with the average values available for all the European countries showing that, as the career progresses, the proportion of women in all disciplines typically decreases (e.g., European Commission, 2019).

Although the scissor graph (Fig. 1) was constructed using data from 2012 and 2014, since data for PhD stu- 
Table 1. Percentages of female Ph.D. students in European countries in 2016 (data source: EUROSTAT, https://ec.europa.eu/ eurostat/home?, last access: 31 October 2019).

\begin{tabular}{llll}
\hline & 2016 & & 2016 \\
\hline Italy & 50.76 & Malta & 50.00 \\
EU-28 countries & 47.77 & Netherlands & 49.01 \\
Belgium & 46.71 & Austria & 46.38 \\
Bulgaria & 51.47 & Poland & 54.63 \\
Czechia & 43.80 & Portugal & 52.36 \\
Denmark & 51.02 & Romania & 49.13 \\
Germany & 44.31 & Slovenia & 52.17 \\
Estonia & 57.14 & Slovakia & 47.56 \\
Ireland & 51.19 & Finland & 52.82 \\
Greece & 45.37 & Sweden & 47.34 \\
Spain & 49.64 & United Kingdom & 47.79 \\
France & 46.97 & Iceland & 60.00 \\
Croatia & 56.25 & Liechtenstein & 50.00 \\
Cyprus & 53.85 & Norway & 51.28 \\
Latvia & 60.87 & Switzerland & 46.31 \\
Lithuania & 59.26 & North Macedonia & 50.00 \\
Luxembourg & 50.00 & Serbia & 56.44 \\
Hungary & 50.68 & Turkey & 41.46 \\
\hline
\end{tabular}

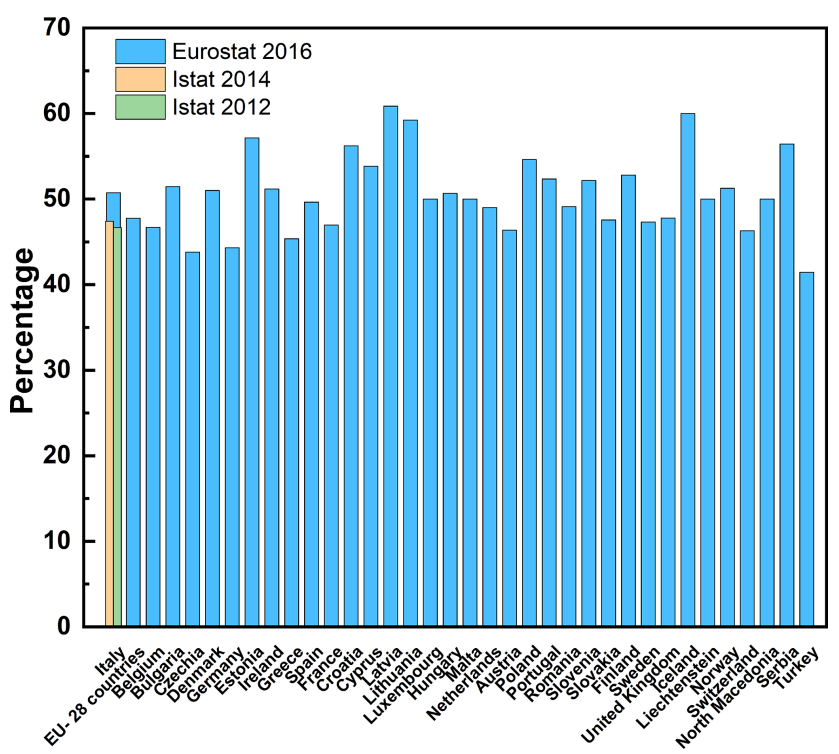

Figure 2. Percentages of female Ph.D. students in all disciplines in Europe and Italy in 2016 (source data: EUROSTAT, https://ec. europa.eu/eurostat/home?, last access: 31 October 2019). Data for $\mathrm{PhD}$ students in Italy for 2014 and 2012 are also reported (source data: ISTAT, https://www.istat.it/, last access: 31 October 2019).

dents were available only for those two years, our aim was to analyse a 19-year interval looking at data for associate and full professors available for December 2001 and 2009 and October 2019. The three datasets are reported in Table $2-4$, respectively, and are taken from the open database of MIUR (https://cercauniversita.cineca.it/

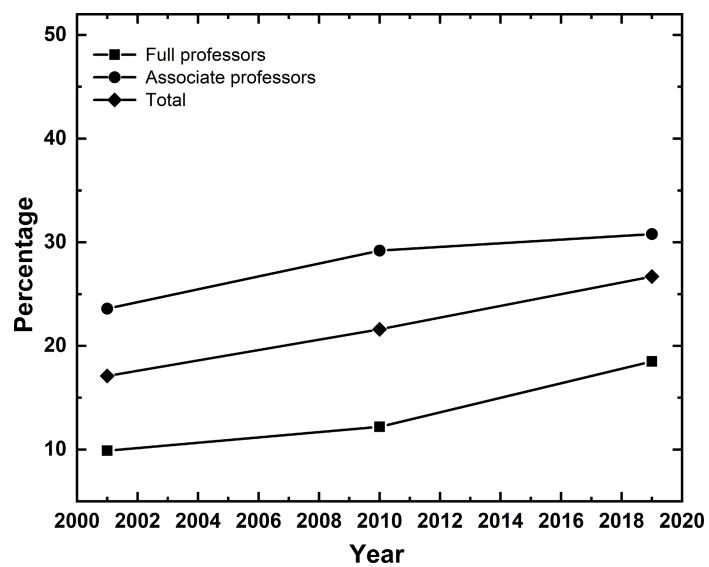

Figure 3. Percentages of female full and associate professors in geosciences in Italy relative to 2001-2019 time span (data source: MIUR, https://cercauniversita.cineca.it/php5/docenti/cerca. php, last access: 31 October 2019).

php5/docenti/cerca.php, last access: 31 October 2019). The general scenario provided is briefly discussed below:

- Situation at 31 December 2001: the total number of professors (full and associate) in geosciences in Italian universities was 872: 388 full professors and 484 associate professors (Table 2). Within the group of full professors, only 35 were female, corresponding to a percentage of $9.0 \%$. Considering associate professors, only $114(23.6 \%)$ were female. Overall, at the end of 2001, 149 out of 872 full and associated professors were female, corresponding to $17.1 \%$ (Fig. 3).

- Situation at 31 December 2009: the total number of professors in geosciences was 722; of which 321 full professors and 401 associate professors (Table 3). With regard to full professors, 39 were female $(12.2 \%)$ while there were $116(28.9 \%)$ female associated professors. Considering both positions, 155 out of 722 were female, a mere $21.4 \%$ (Fig. 3).

- Situation at October 2019: the same analysis, presented in Table 4, shows a significant decline in the overall number of professors in geosciences - from 872 to 674 (ca. $-23 \%$ ), while the number of female professors increased substantially: of the total 205 full professors, $38(18.5 \%)$ were female, while of the 469 associate professors $142(30.8 \%)$ were female. Overall, if we consider the complete number of 674 professors, $180(26.7 \%)$ were female hence representing a ca. $5 \%$ increase with respect to situation at the end of 2009 (Fig. 3).

The trend at the end of 2001, 2009 and in October 2019 is distinct: full and associate female professors in geosciences within Italian universities are slowly, but definitively, increasing. Figure 3 highlights the percentage of female full and as- 
Table 2. Number of full and associate professors in all GEO scientific SSD (from 01 to 12 ) of the Italian university system relative to December 2001 (data source: MIUR, https://cercauniversita.cineca. it/php5/docenti/cerca.php, last access: 31 October 2019).

\begin{tabular}{|c|c|c|c|c|c|c|}
\hline \multicolumn{7}{|c|}{ December 2001} \\
\hline & \multicolumn{3}{|c|}{ Full professors } & \multicolumn{3}{|c|}{ Associate professors } \\
\hline & Female & Male & Total & Female & Male & Total \\
\hline GEO/01 & 10 & 28 & 38 & 27 & 22 & 49 \\
\hline GEO/02 & 6 & 62 & 68 & 12 & 62 & 74 \\
\hline GEO/03 & 2 & 31 & 33 & 8 & 41 & 49 \\
\hline GEO/04 & 1 & 28 & 29 & 11 & 49 & 60 \\
\hline GEO/05 & 0 & 44 & 44 & 6 & 48 & 54 \\
\hline GEO/06 & 5 & 31 & 36 & 20 & 23 & 43 \\
\hline GEO/07 & 4 & 42 & 46 & 8 & 30 & 38 \\
\hline GEO/08 & 3 & 28 & 31 & 7 & 25 & 32 \\
\hline GEO/09 & 1 & 22 & 23 & 7 & 25 & 32 \\
\hline GEO/10 & 1 & 19 & 20 & 5 & 22 & 27 \\
\hline GEO/11 & 2 & 14 & 16 & 3 & 14 & 17 \\
\hline GEO/12 & 0 & 4 & 4 & 1 & 8 & 9 \\
\hline Total & 35 & 353 & 388 & 115 & 369 & 484 \\
\hline
\end{tabular}

sociate professors, plus the total number of professors as a function of time. For full professors, over the 19-year period, the percentage increased from $9.0 \%$ to $18.5 \%$, the number of female full professors doubled. However, if such trend were to continue in the future, as seen over the 19 years considered, we would reach a gender balance around 2090, hence in about 70 years from now. To check the detailed trend of the decrease of full professors through time we have also collected the annual data which point to a less positive and more articulated scenario described in the next section.

In the case of associate professors, Fig. 3 presents a positive trend, with the percentage of female associate professors rising from $23.6 \%$ to $28.9 \%$. This implies that a gender balance could be reached around the year 2070, a better scenario than the one predicted for full professors, but still an excessively slow trend.

Finally, Fig. 3 also presents the percentage of the total number of full and associate professors as a function of time, indicating a linear trend, which saw an increase of the percentage of female professors from $17.1 \%$ to $26.7 \%$ during the given period.

\section{Distribution of female professors in different geosciences areas in Italy}

As mentioned in the introduction, geosciences in the Italian university system are classified in 12 different areas. In this paragraph, the differences in the distribution of female professors in the different areas (Fig. 4) will be examined based on the data reported in Tables $2-4$, considering the period between the end of 2001 and October 2019.
Table 3. Number of full and associate professors in all GEO scientific SSD (from 01 to 12 ) of the Italian university system relative to December 2009 (data source: MIUR, https://cercauniversita.cineca. it/php5/docenti/cerca.php, last access: 31 October 2019).

\begin{tabular}{|c|c|c|c|c|c|c|}
\hline \multicolumn{7}{|c|}{ December 2009} \\
\hline & \multicolumn{3}{|c|}{ Full professors } & \multicolumn{3}{|c|}{ Associate professors } \\
\hline & Female & Male & Total & Female & Male & Total \\
\hline GEO/01 & 11 & 18 & 29 & 27 & 17 & 44 \\
\hline GEO/02 & 6 & 34 & 40 & 13 & 52 & 65 \\
\hline GEO/03 & 3 & 26 & 29 & 3 & 27 & 30 \\
\hline GEO/04 & 1 & 27 & 28 & 13 & 39 & 52 \\
\hline GEO/05 & 2 & 40 & 42 & 8 & 35 & 43 \\
\hline GEO/06 & 8 & 27 & 35 & 13 & 17 & 30 \\
\hline GEO/07 & 2 & 28 & 30 & 8 & 25 & 33 \\
\hline GEO/08 & 2 & 25 & 27 & 11 & 19 & 30 \\
\hline GEO/09 & 3 & 16 & 19 & 4 & 19 & 23 \\
\hline GEO/10 & 0 & 24 & 24 & 9 & 17 & 26 \\
\hline GEO/11 & 1 & 14 & 15 & 5 & 11 & 16 \\
\hline GEO/12 & 0 & 3 & 3 & 2 & 7 & 9 \\
\hline Total & 39 & 282 & 321 & 116 & 285 & 401 \\
\hline
\end{tabular}

Table 4. Number of full and associate professors in all GEO scientific SSD (from 01 to 12 ) of the Italian university system relative to October 2019 (data source: MIUR, https://cercauniversita.cineca.it/ php5/docenti/cerca.php, last access: 31 October 2019).

October 2019

\begin{tabular}{lrrrrrrrr}
\hline & \multicolumn{3}{c}{ Full professors } & & \multicolumn{3}{c}{ Associate professors } \\
\cline { 2 - 5 } \cline { 7 - 8 } & Female & Male & Total & & Female & Male & Total \\
\hline GEO/01 & 9 & 9 & 18 & & 21 & 19 & 40 \\
GEO/02 & 6 & 19 & 25 & & 14 & 47 & 61 \\
GEO/03 & 3 & 27 & 30 & & 15 & 38 & 53 \\
GEO/04 & 3 & 23 & 26 & & 13 & 51 & 64 \\
GEO/05 & 5 & 19 & 24 & & 13 & 42 & 55 \\
GEO/06 & 4 & 13 & 17 & & 14 & 17 & 31 \\
GEO/07 & 4 & 15 & 19 & & 8 & 28 & 36 \\
GEO/08 & 2 & 12 & 14 & & 12 & 26 & 38 \\
GEO/09 & 0 & 4 & 4 & & 13 & 21 & 34 \\
GEO/10 & 1 & 13 & 14 & & 11 & 19 & 30 \\
GEO/11 & 0 & 7 & 7 & & 5 & 14 & 19 \\
GEO/12 & 1 & 6 & 7 & & 3 & 5 & 8 \\
\hline Total & 38 & 167 & 205 & & 142 & 327 & 469 \\
\hline
\end{tabular}

The overall trend observed for each single SSD is characterized by an increase of the female percentage both in the full and associate professor population, with some peculiar exceptions, which require discussion.

Relatively to full professors, higher percentages of women are present in GEO/01, which furthermore witnessed a significant increase: from $26 \%$ to $50 \%$, while GEO/02 rose from $9 \%$ to $24 \%$ and GEO/06 from $14 \%$ to $24 \%$. However, the most remarkable is GEO/05, which jumped from $0 \%$ to $21 \%$. 

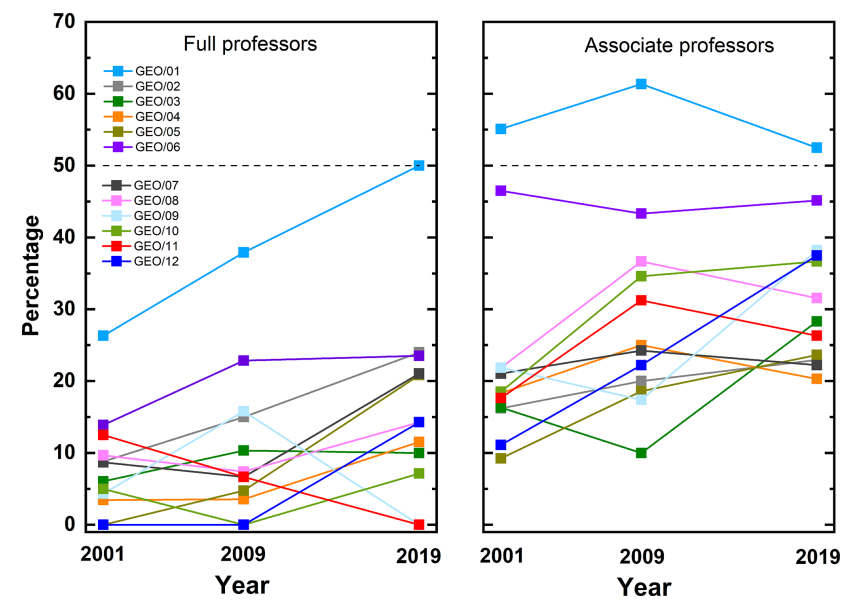

Figure 4. Percentages of female full and associate professors in all GEO scientific areas (from GEO/01 to GEO/12) of the Italian university system relative to 2001-2019 time span (data source: MIUR, https://cercauniversita.cineca.it/php5/docenti/cerca. php, last access: 31 October 2019).

On the other side, extremely negative trends are evident in GEO/11 and GEO/09, which at present do not have any female full professors. GEO/10, GEO/03 and GEO/04 instead present more complicated trends, with percentages of female full professors generally increasing, but still below $10 \%$.

The comparison among associate professors of the different SSD (Fig. 4) confirms the achievement of gender equality in $\mathrm{GEO} / 01$, as the percentage varies between $53 \%$ and $61 \%$, and in GEO/06, where it ranges between $43 \%$ and $47 \%$. Positive trends are moreover evident for GEO/09, GEO/10 and GEO/12, which show a percentage close to $40 \%$. Percentages below or close to $30 \%$ characterize the remaining SSD, which definitively suffer of a significant gender imbalance.

\section{Regional distribution and Glass ceiling index: Northern, Central and Southern Italy}

In this paragraph, we will analyse the distribution of female professors and the Glass Ceiling Index in the Northern, Central and Southern part of Italy. Compared to the national trend of full and associate professors, the regional proportion of female is consistent with the increase recorded in Italy (Fig. 5). However, the percentages of female full professors in 2019 are lower in the South. The increase in the proportion of women is also visible for associate professors both at the national and regional level, although slightly lower values are recorded in Central Italy ( $<30 \%$; Table 5; Fig. 5).

Overall, it is evident that the presence of female professors is reasonably well distributed over the three different geographical areas in Italy during the 2001-2009 period, with national average values of full professor never exceeding $12 \%$. More interesting is the trend of associated professors displaying a national increase starting from 2004-2005 that is visible even if slightly intensified or attenuated in the different areas of the country (Fig. 5).

At both national and regional level, a remarkable increase (from $\sim 12 \%$ to $\sim 19 \%$ ) of female full professors is observed from $2009 / 2010$ to $2012 / 2013$ (Fig. 5). This radical change temporally coincides with the promulgation of the Italian Laws no. 240/2010 and 214/2011 and retirement of $30 \%$ of male full professors, resulting in the absolute number of female full professors remaining substantially unchanged while that of men being reduced dramatically in this interval.

A feature that raises some concerns comes for Southern Italy, as in the last 2-3 years (2017-2019) the number of female full professors fell from 13 to $9(<15 \%)$ (Fig. 5; Table 5). This tendency appears opposite to the one displayed in Northern Italy $(+\sim 5 \%)$ and different from Central Italy, which essentially remains constant (Fig. 5; Table 5).

During the 2010-2019 decade, the number of associate professors instead presents an overall slightly increase $(+2.3 \%)$ at national level, more prominent in the South $(+4.4 \%)$, less accentuated in the North $(+2.3 \%)$ and absent in Central Italy (Fig. 5).

The regional distribution does not show any substantial difference with the national scenario in terms of female relative percentages, except for the aforementioned decrease in female full professors in the South and some other minor trends. However, since these values are well below the gender equality we have decided to calculate the Glass Ceiling Index both at national and regional level. The GCI is the ratio between the proportion $(\%)$ of the total number of women in academia (i.e. full professors, associate professors and researchers) and the total number of top academic positions (i.e. full professors) compared with the same ratio calculated for men in a given year (European Commission, 2006, p. 52). This ratio varies from 0 to infinite, where a value equal to 1 indicates no difference between women and men in terms of their chances of being promoted. Values higher than 1, instead, mean that women are facing greater difficulties than men in advancing to the highest academic positions (European Commission, 2019). For European countries, the mean GCI value for all the disciplines in 2013 and 2016 is 1.64 and 1.68, respectively, while for Italy it is slightly higher (1.68 and 1.73, respectively) (European Commission, 2019).

Based on the dataset provided by the MIUR we have calculated the GCI for Italian geosciences from 2001 to 2019. The national value (Table 6) shows a progressive negative trend, i.e. has varied from $\sim 3$ in the decade 2000-2010 to values slightly lower that 2 in the following decade (2010-2019) (Fig. 6). Although this scenario seems overall positive during the period considered, the data are not yet satisficing as they evidence a clear barrier for women in geosciences (Fig. 6). At regional level, the GCI seems to be comparable for Northern and Central Italy, however, it displays a counter tendency from 2017 on for the South, where the values are $\sim 2.5-3$ (Fig. 6). As mentioned above, this is obviously related to the 

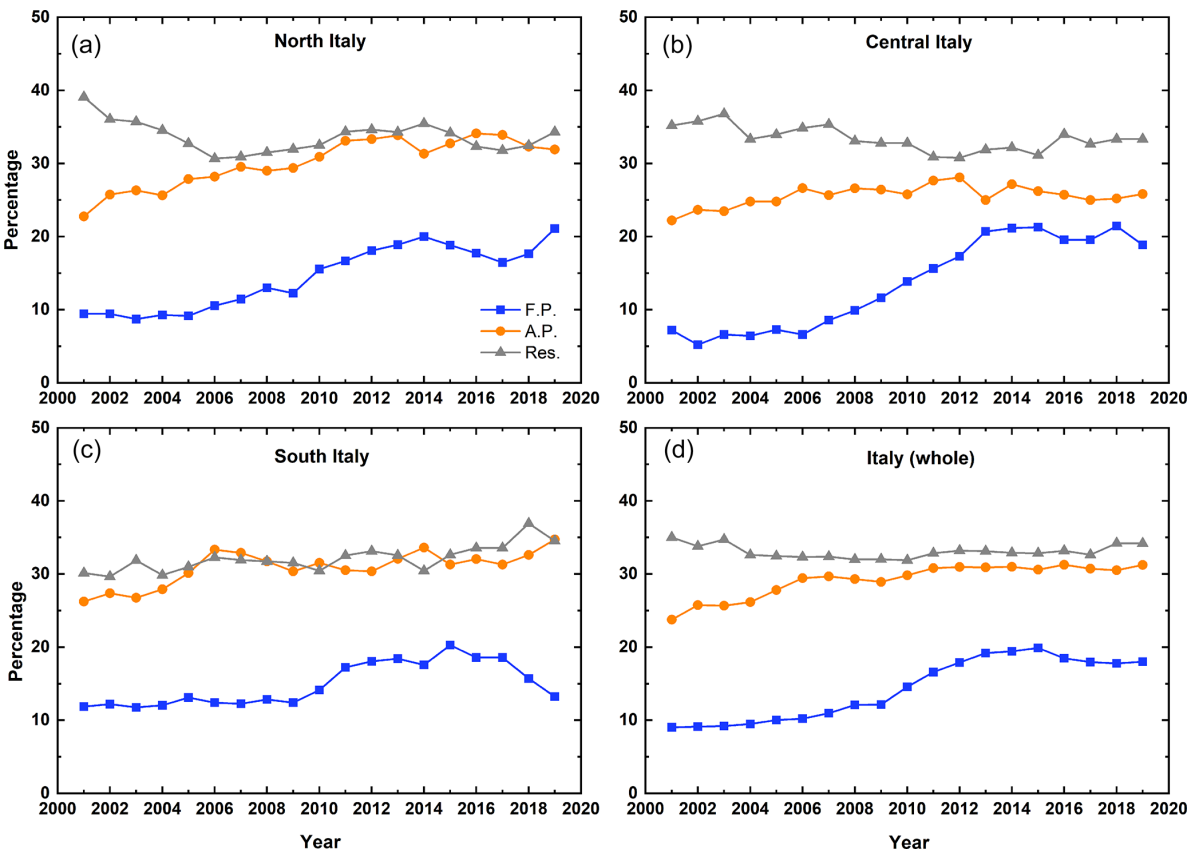

Figure 5. Proportion (\%) of female academic staff (F. P.: full professors; A. P.: associated professors and Res: Researchers) from 2001 to 2019 in (a) Northern; (b) Central; (c) Southern Italy; (d) whole Italy, (data source: MIUR, https://cercauniversita.cineca.it/php5/docenti/cerca.php, last access: 31 October 2019).

Table 5. Geographical distribution (\%) of female professors over Northern (N including Aosta Valley, Emilia-Romagna, Friuli Venezia Giulia, Liguria, Lombardy, Piedmont, and Veneto), Central (C including Lazio, Marche, Tuscany ed Umbria) and Southern (S including Abruzzo, Basilicata, Calabria, Campania, Molise, Puglia, Sardinia and Sicily) Italy from 2001 to 2019. National data are also provided for comparison (data source: MIUR, https://cercauniversita.cineca.it/php5/docenti/cerca.php, last access: 31 October 2019).

\begin{tabular}{|c|c|c|c|c|c|c|c|c|c|c|c|c|}
\hline \multirow{2}{*}{$\begin{array}{l}\text { Female } \\
\%\end{array}$} & \multicolumn{3}{|c|}{ Italy } & \multicolumn{3}{|c|}{ North } & \multicolumn{3}{|c|}{ Central } & \multicolumn{3}{|c|}{ South } \\
\hline & FP & $\mathrm{AP}$ & Res & FP & $\mathrm{AP}$ & Res & FP & $\mathrm{AP}$ & Res & FP & $\mathrm{AP}$ & Res \\
\hline 2001 & 9.0 & 23.8 & 35.0 & 9.4 & 22.8 & 39.1 & 7.2 & 22.2 & 35.2 & 11.9 & 26.3 & 30.1 \\
\hline 2002 & 9.1 & 25.8 & 33.8 & 9.4 & 25.8 & 36.0 & 5.2 & 23.7 & 35.8 & 12.2 & 27.4 & 29.7 \\
\hline 2003 & 9.2 & 25.7 & 34.7 & 8.7 & 26.3 & 35.7 & 6.6 & 23.5 & 36.8 & 11.8 & 26.8 & 31.9 \\
\hline 2004 & 9.5 & 26.2 & 32.6 & 9.3 & 25.7 & 34.5 & 6.4 & 24.8 & 33.3 & 12.1 & 27.9 & 29.9 \\
\hline 2005 & 10.0 & 27.8 & 32.5 & 9.2 & 27.9 & 32.7 & 7.3 & 24.8 & 34.0 & 13.1 & 30.1 & 31.0 \\
\hline 2006 & 10.2 & 29.4 & 32.3 & 10.6 & 28.2 & 30.7 & 6.6 & 26.6 & 34.9 & 12.4 & 33.3 & 32.3 \\
\hline 2007 & 11.0 & 29.7 & 32.4 & 11.5 & 29.5 & 30.9 & 8.6 & 25.7 & 35.3 & 12.2 & 32.9 & 31.9 \\
\hline 2008 & 12.1 & 29.3 & 32.0 & 13.0 & 29.0 & 31.5 & 9.9 & 26.6 & 33.1 & 12.9 & 31.7 & 31.7 \\
\hline 2009 & 12.1 & 28.9 & 32.0 & 12.3 & 29.4 & 32.0 & 11.6 & 26.4 & 32.8 & 12.4 & 30.4 & 31.5 \\
\hline 2010 & 14.6 & 29.8 & 31.9 & 15.6 & 30.9 & 32.5 & 13.8 & 25.8 & 32.8 & 14.1 & 31.5 & 30.4 \\
\hline 2011 & 16.6 & 30.8 & 32.9 & 16.7 & 33.1 & 34.3 & 15.6 & 27.7 & 30.9 & 17.2 & 30.5 & 32.5 \\
\hline 2012 & 17.9 & 31.0 & 33.2 & 18.1 & 33.3 & 34.6 & 17.3 & 28.1 & 30.8 & 18.1 & 30.4 & 33.1 \\
\hline 2013 & 19.2 & 30.9 & 33.1 & 18.9 & 33.9 & 34.3 & 20.7 & 25.0 & 31.9 & 18.4 & 32.1 & 32.6 \\
\hline 2014 & 19.4 & 31.0 & 32.9 & 20.0 & 31.3 & 35.5 & 21.2 & 27.2 & 32.2 & 17.6 & 33.6 & 30.4 \\
\hline 2015 & 19.9 & 30.6 & 32.8 & 18.8 & 32.7 & 34.2 & 21.3 & 26.2 & 31.1 & 20.3 & 31.3 & 32.6 \\
\hline 2016 & 18.5 & 31.3 & 33.2 & 17.7 & 34.1 & 32.3 & 19.6 & 25.7 & 34.0 & 18.6 & 32.0 & 33.6 \\
\hline 2017 & 17.9 & 30.7 & 32.6 & 16.5 & 33.9 & 31.8 & 19.6 & 25.0 & 32.7 & 18.6 & 31.3 & 33.6 \\
\hline 2018 & 17.8 & 30.5 & 34.2 & 17.6 & 32.3 & 32.5 & 21.4 & 25.2 & 33.3 & 15.7 & 32.6 & 36.9 \\
\hline 2019 & 18.0 & 31.2 & 34.2 & 21.1 & 31.9 & 34.3 & 18.9 & 25.8 & 33.3 & 13.2 & 34.7 & 34.5 \\
\hline
\end{tabular}




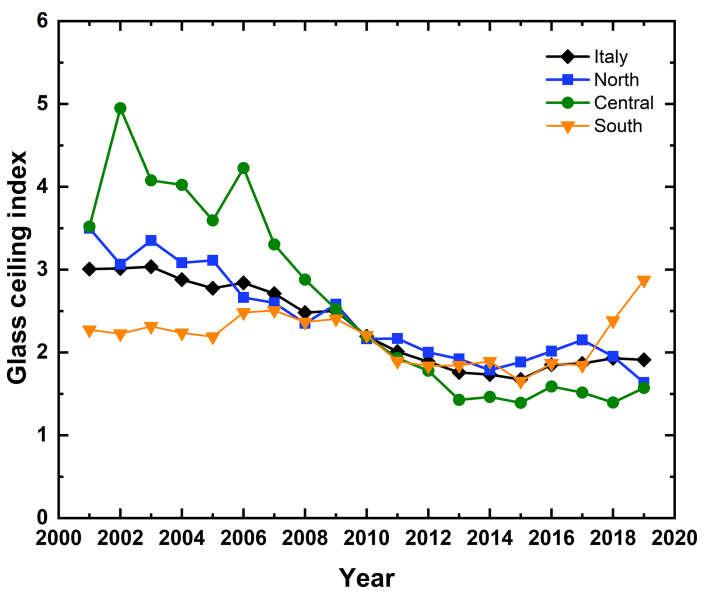

Figure 6. Glass Ceiling Index (GCI) calculated in Italy from 2001 to 2019. GCI is also provided for Northern, Central and Southern Italy (data source: MIUR, https://cercauniversita.cineca.it/php5/ docenti/cerca.php, last access: 31 October 2019).

Table 6. Glass ceiling index. National average and specific indexes calculated for Northern, Central and Southern Italy from 2001 to 2019 (data source: MIUR, https://cercauniversita.cineca.it/php5/ docenti/cerca.php, last access: 31 October 2019).

\begin{tabular}{ccccc}
\hline GCI & Italy & North & Central & South \\
\hline 2001 & 3.01 & 3.50 & 3.52 & 2.27 \\
2002 & 3.02 & 3.06 & 4.95 & 2.23 \\
2003 & 3.03 & 3.35 & 4.08 & 2.32 \\
2004 & 2.88 & 3.08 & 4.02 & 2.24 \\
2005 & 2.78 & 3.11 & 3.59 & 2.19 \\
2006 & 2.84 & 2.66 & 4.23 & 2.48 \\
2007 & 2.71 & 2.60 & 3.30 & 2.51 \\
2008 & 2.48 & 2.35 & 2.88 & 2.37 \\
2009 & 2.50 & 2.58 & 2.52 & 2.41 \\
2010 & 2.20 & 2.16 & 2.19 & 2.21 \\
2011 & 2.01 & 2.17 & 1.93 & 1.89 \\
2012 & 1.89 & 2.00 & 1.78 & 1.84 \\
2013 & 1.76 & 1.92 & 1.43 & 1.85 \\
2014 & 1.73 & 1.79 & 1.46 & 1.89 \\
2015 & 1.67 & 1.88 & 1.39 & 1.65 \\
2016 & 1.85 & 2.02 & 1.59 & 1.87 \\
2017 & 1.87 & 2.15 & 1.52 & 1.85 \\
2018 & 1.93 & 1.95 & 1.39 & 2.38 \\
2019 & 1.91 & 1.64 & 1.57 & 2.87 \\
\hline
\end{tabular}

absolute and relative decrease of full professors in Southern Italy.

\section{Geosciences versus all other disciplines in Italy: a comparison}

After a first analysis of the presence of female professors in geosciences, a comparison between women in geosciences

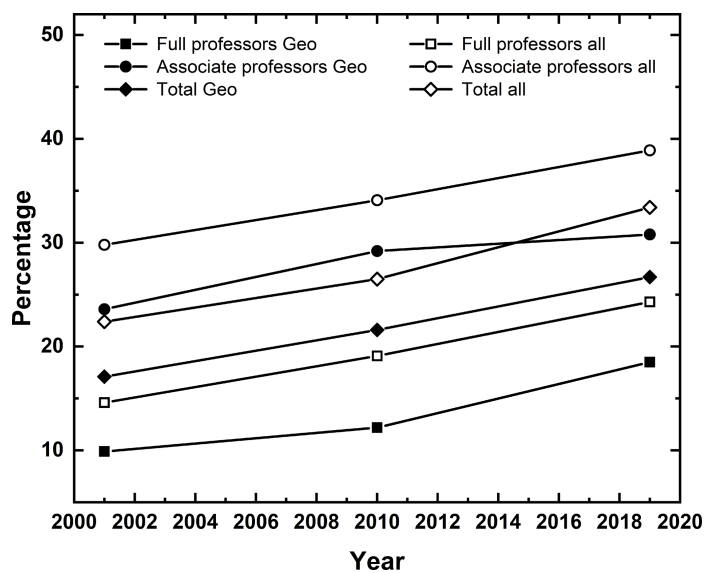

Figure 7. Comparison between percentages of female professors (F. P.: full professors; A. P.: associated professors; T. P.: total number of professors) in geosciences (indicated as GEO) and the average from all Italian disciplines (indicated as ALL) (data source: MIUR, https://cercauniversita.cineca.it/php5/docenti/cerca. php, last access: 31 October 2019).

versus the entire Italian university system, i.e. all the 14 scientific areas, is necessary.

The official data for the 14 areas is reported in Table 7, whereas the comparison between the sum of data from all 14 areas and that of geosciences (Area 04 - Earth Sciences) is shown in Fig. 7. Figure 7 proves that the number of female professors in geosciences is significantly lower than the national average, both at full and associate professor level. In detail, we observe that the national percentage (14 areas) of female full professors increased from $14.6 \%$ at the end of 2001 to $24.3 \%$ in October 2019 , i.e. nearly $6 \%$ above the value of female full professors in geosciences in 2019. A similar trend is evident for the associate professors in all areas, with an increase from $29.8 \%$ at the end of 2001 to $38.9 \%$ in 2019 , hence $8.1 \%$ higher than what found in geosciences. Finally, considering the sum of full and associate professors from all the areas, the number increased from $22.4 \%$ at the end of 2001 to $33.4 \%$ in 2019 , about $6.7 \%$ higher than the total number of female professors in geosciences.

\section{Geosciences versus all other related disciplines (STEM) in Italy}

The lower proportion of full and associate professors in geosciences observed above is consistent with European data showing that STEM disciplines typically present a strong gender imbalance with the gap becoming wider as the career progresses (e.g., EIGE, 2017a; European Commission, 2019; Sattari and Sandefur, 2019).

In order to better understand this phenomenon, we performed a further comparison with scientific areas considered closer to geosciences, the so called STEM disciplines, such 
Table 7. Total number of full and associate professors and their sum for the end of 2001, end of 2009 and October 2019 in the Italian university system (data source: MIUR, https://cercauniversita.cineca.it/php5/docenti/cerca.php, last access: 31 October 2019).

\begin{tabular}{|c|c|c|c|c|c|c|c|c|}
\hline \multicolumn{3}{|c|}{ Full professors } & \multicolumn{3}{|c|}{ Associate professors } & \multicolumn{3}{|c|}{ Total number of professors } \\
\hline $\mathrm{F}$ & M & Total & $\mathrm{F}$ & M & Total & $\mathrm{F}$ & M & Total \\
\hline \multicolumn{9}{|c|}{ End of 2001} \\
\hline 2468 & 14424 & 16892 & 5325 & 12551 & 17876 & 7793 & 26975 & 34768 \\
\hline \multicolumn{9}{|c|}{ End of 2009} \\
\hline 3422 & 14456 & 17878 & 5985 & 11580 & 17565 & 9407 & 26036 & 35443 \\
\hline 3170 & 9897 & 13067 & 8421 & 13236 & 21657 & 11591 & 23133 & 34724 \\
\hline
\end{tabular}

as mathematics and informatics (area - 01), physics (area - 02, chemistry (area -03), civil engineering and architecture (area - 08) and industry engineering and informatics (area - 09). In Fig. 8, we show the comparison among data at the end of 2001 until October 2019. Empty symbols represent the average values calculated for all the areas mentioned above (i.e. areas 01, 02, 03, 08 and 09) and do not include data from geosciences (i.e. area 04) indicated with full symbols. In detail, relatively to full professors, we observe a slightly better, although poorly significant, gender balance in geosciences with differences ranging between $+1 \%$ (end of 2001) $+0.9 \%$ (end of 2009) and $+1.2 \%$ (October 2019). A similar trend is evident for associate professors, with a better balance in geosciences, with $+1.3 \%$ at end of $2001,+3.3 \%$ at the end of 2009 and only $+0.6 \%$ at October 2019. Both trends thus account for a slightly better gender balance in geosciences when considering both full and associate professors, displaying a positive balance of $+1.1 \%$ (end of 2001), +3\% (end of 2009) and 1.2\% (October 2019), respectively.

Overall, on one side, it is clear that geosciences show a better gender balance compared to related scientific areas, while on the other side, some concerns could be expressed when analysing the "increase rate" in terms of associate professors. In fact, a slight but significant decrease can be noticed, which could impact the possibility of increasing the number of female full professors in geosciences in the future.

It is worth saying that, in STEM disciplines at the M.Sc. level, the proportion of female students is low and progressively further decreases at each step, that is for $\mathrm{PhD}$ students, researcher, associate and full professor positions. In geosciences, on the other hand, the female percentages through the academic career are slightly better, nonetheless it is important to consider the anomalous high percentage of female $\mathrm{PhD}$ graduates which should have produced an increase in the presence of female academic staff. This, however, is not the case, suggesting that obtaining an academic permanent position is the first main obstacle an Italian female geoscientist has to face, the so-called Glass Door (Hassink and Russo, 2010).

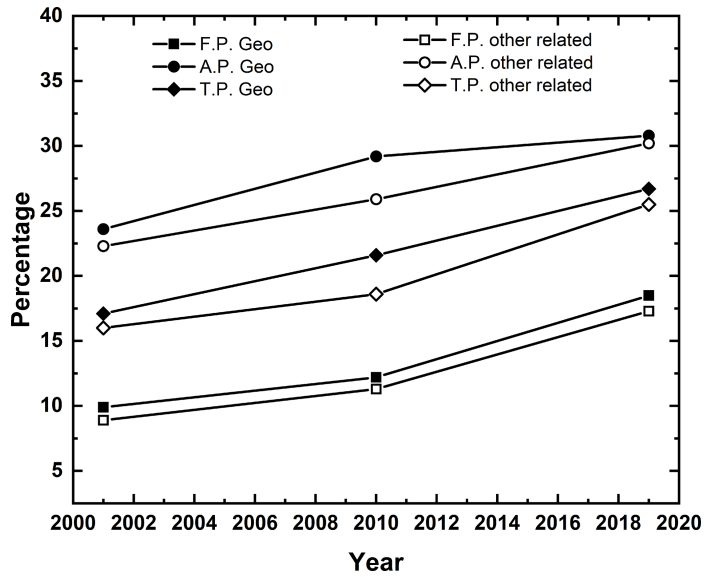

Figure 8. Comparison between percentages of female professors in geosciences and the average from the scientific areas considered closer to geosciences like area - 01 (mathematics and informatics), area - 02 (physics), area - 03 (chemistry), area 08 (civil engineering and architecture) and area - 09 (industry engineering and informatics) (see Fig. 7 for symbols) (data source: MIUR, https://cercauniversita.cineca.it/php5/docenti/cerca. php, last access: 31 October 2019).

\section{A comparison at international level in geosciences}

Comparing international university systems is not an easy task but limiting the comparison to full and associate professors should ensure a certain degree of reliability. Nevertheless, one crucial problem usually faced is that the source of the available official data, not always recent or updated, may not be provided by public entities, which instead happens in Italy where data is provided directly by the MIUR. Below, a comparison between the Italian, American and German university systems has been provided.

In the American system, local universities distinguish between full and associate professors, as in the Italian system, thus allowing a direct comparison. However, in the German system there is no distinction between full and associate professors, seen that this system only has "professors", who are 
then classified in $\mathrm{W} 1, \mathrm{~W} 2$ and $\mathrm{W} 3$ professors, with $\mathrm{W} 2$ and W3 comparable to full professors, and W1 to "junior professors".

\subsection{Italian versus American system}

Relatively to the American university system, Holmes et al. (2008) and Holmes (2017) show thatfemale full professors were only $8 \%$ in 2000-2001 and did not increase by 2004-2005. Furthermore, female associate professors were $15 \%$ in $2000-2001$ and remained constant in 20042005 (14\%). However, Glass (2015) reports that in the academic year 2010-2011 women in full professor positions were $13 \%$ while in associate professor positions they were $24 \%$. The percentages reported by Glass (2015) were collected throughout the 106 top US Earth Science PhD-ranting graduate programmes during the 2010-2011 academic year. The data presented by Glass (2015) was further confirmed by Wilson (2016), who compared 2006 and 2016. In such work, the percentage of female full professors in 2006 was $8.9 \%$ and increased to about $15 \%$ in 2016 . Relatively to female associate professors, Wilson (2016) reported that the percentage was around $16 \%$ in 2006 and close to $25 \%$ in 2016.

Combining the data collected by Holmes et al. (2008), Glass (2015) and Wilson (2016), a rather reliable scenario appears with regard to the percentage of female professors in the American university system between 2001 and 2016, showing an increase from $8 \%$ to $15 \%$ when considering full professors and from $15 \%$ to $25 \%$ in the case of associate professors.

Comparing such data with the Italian university system and considering the same period of time, the percentage of female full professors was about $9 \%$ at the end of 2001 and $18.6 \%$ at the end of 2016 (data from the MIUR). In terms of associate professors, at the end of 2001, the Italian system showed $23.6 \%$, whereas at the end of 2016 , the number increased to $31.3 \%$. Thus, the Italian system shows a significantly better gender balance relatively to the percentage of both full and associate professors. The reciprocal increase rate, instead, is quite similar.

\subsection{Italian versus German system}

A snapshot of the female proportion in the European universities taken in 2016, revealed that women made up $46 \%$ of researcher positions, $40 \%$ of associate professors and $24 \%$ of full professors, when all disciplines are considered. Again, these values are lower if STEM disciplines are examined (European Commission, 2019). In order to directly compare the situation in geosciences, we have decided to do it against Germany as all the necessary information is available. Official data for the German university system was retrieved from the Statistisches Bundesamt (DESTATIS, 2019) reports published in 2018, 2011 and 2004, which describe the situation in 2017, 2010 and 2003, respectively. This database only reports "professoren" (professors) for "geowissenschaften" (Earth sciences) and since the distinction among W1-W3 professors is recent, they do not indicate it.

In detail, for geosciences (excluding geography), the German system counts a percentage of female professors equal to $4.3 \%$ in $2003,12.4 \%$ in 2010 and $15.3 \%$ in 2017. During the same years, in Italy we observe $9.2 \%$ female full professors at the end of 2003, $14.6 \%$ at the end of 2010 and $17.9 \%$ at the end of 2017 , a value close to $+2.5 \%$ compared to the percentage of female professors in Germany. However, it is evident that the German trend signals a stronger increase than the Italian trend (in 2003 the difference was $+5.7 \%$ for Italy and in 2017 only $+2.9 \%$ ), especially considering that the annual record available for Italy shows that the increase rate is close to zero starting from 2013 (Fig. 5).

\section{Future perspectives and possible clues}

The choice of comparing merely associate and full professors has granted a statistically consistent analysis, even if, when necessary, we have also made some comments on other academic and non-academic positions. The results described, however, represent only the final stage of a "gender inequality" phenomenon. An additional perspective to achieve a broader view of gender balance is provided by the gender distribution of the geoscience student population in Italy. We have selected official data from the open data source Alma Laurea (https://www.almalaurea.it, last access: 31 October 2019) relatively to 2009 and 2018, the last update data available, for the bachelor degree in Geological Sciences (for the MIUR, this degree is labelled as L-34) and for the master degree in Geological Sciences and Technology (LM74). These data show that out of a total of 1485 students who obtained a degree, the female population accounted for $36.1 \%$ in L-34 and $36.6 \%$ in LM-74 in 2018. The numbers are virtually identical if compared to those of 2009 . Moving a step forward in their career, we see that the average national percentage of $\mathrm{PhD}$ degree obtained in basic science (including mathematics and informatics, physics, chemistry and geosciences) by female students varies from $51 \%$ to $36 \%$ in the time window comprised from 2015 and 2018 (https://www.almalaurea.it, last access: 31 October 2019) and, more interestingly was equal to 51.3 and 49.4 for the female geoscientists in 2014 and 2012 respectively (https://www.istat.it/, last access: 31 October 2019). This confirms the substantial gender equality at the $\mathrm{PhD}$ level resulting from the increased proportion of women compared to the number of female MSc students (Fig. 1).

The comparison between the student dataset (i.e. undergraduate, $\mathrm{MSc}$ and $\mathrm{PhD}$ students) and the average value of female associate and full professors $(30.2 \%$ and $18.5 \%)$ confirms that the female proportion of $\mathrm{PhD}$ student population is not echoed by the numbers of associate and full professors (Fig. 1). 
Table 8. Total number, male and female number and percentages of different types of permanent and non-permanent researchers positions for the end of 2001, end of 2009 and October 2019 in the Italian university system (data source: MIUR, https://cercauniversita. cineca.it/php5/docenti/cerca.php, last access: 31 October 2019).

\begin{tabular}{|c|c|c|c|c|}
\hline & $\begin{array}{r}\text { Permanent } \\
\text { researchers } \\
(\mathrm{RTI})\end{array}$ & $\begin{array}{r}\text { Non- } \\
\text { permanent } \\
\text { researchers } \\
(2005)\end{array}$ & $\begin{array}{r}\text { Non- } \\
\text { permanent } \\
\text { RTD-a }\end{array}$ & $\begin{array}{r}\text { Non- } \\
\text { permanent } \\
\text { RTD-b }\end{array}$ \\
\hline \multicolumn{5}{|c|}{ December 2001} \\
\hline M & 258 & & & \\
\hline $\mathrm{F}$ & 142 & & & \\
\hline Total & 400 & & & \\
\hline$\%$ & 35.5 & & & \\
\hline \multicolumn{5}{|c|}{ December 2009} \\
\hline M & 316 & 26 & & \\
\hline $\mathrm{F}$ & 150 & 25 & & \\
\hline Total & 466 & 51 & & \\
\hline$\%$ & 32.2 & 49.0 & & \\
\hline \multicolumn{5}{|c|}{ October 2019} \\
\hline M & 138 & 11 & 52 & 54 \\
\hline $\mathrm{F}$ & 75 & 3 & 31 & 19 \\
\hline Total & 213 & 14 & 83 & 73 \\
\hline$\%$ & 35.2 & 21.4 & 37.4 & 26.0 \\
\hline
\end{tabular}

Thus, an insight in the Italian researcher population is necessary, even if the differences in the type of researcher positions and the substantial impossibility to compare them with other international systems has already been explained (see materials and methods for details). In any case, the observed intervals were the same (i.e. 2001, 2009 and 2019) as shown in Table 8.

The researchers with a permanent position display a progressive decrease in the absolute number caused by the modification implemented by the Italian Law no. 240/2010. However, there is a substantial stability in the percentages of the female component between 2001 and 2019 (34\%) (Fig. 5), similar if compared to the available data for graduate students and $\mathrm{PhDs}$. More interesting is the percentage of RTD-b positions (see the introduction section), which represent a crucial turning point between non-permanent and permanent positions. The average national value for female RTD-b was of $\sim 26.0 \%$ in October 2019, which is a decisive step backward compared to the permanent researcher (RTI) and to RTD-a (i.e. temporary three-years contract positions), which display a significantly higher value of $37.6 \%$. Considering that RTDbs are destined to advance their careers becoming professors, the concern is strong, as gender imbalance becomes a major future risk. To summarize, we observed a positive general increase of the female component in the different academic roles through time (2001-2019), a trend that has attenuated the gender imbalance. However, the number of RTD-b (only $26 \%$ of female at national level) is a clear and alarming countertendency. It is worth noting that the percentages of women and men clearly diverge, in favour of the latter, when they reach the role of permanent researchers and even more dramatically in the case of full professors (Fig. 1).

All considered, the decrease of the female presence at the beginning of the university career (i.e. permanent researcher and RTD-b positions) could likely result from the existence of a structural gender bias in both Italian and foreign university systems. However, it is part of the task of the institutions to conceive, promote and implement supporting actions so that men and women can be given equal opportunities of career advancement. One possibility is to offer work-life balance policies (e.g., childcare, paternity leave, as well as other services), which would facilitate women to continue to work. Even if this approach is necessary and probably effective, this also highlights a patriarchal mentality where women are supposed to be in charge of family duties. More should be done, especially with the aim of changing this prevailing mentality and guaranteeing the same opportunities to men and women. At moment, the only formally positive gender balance in the Italian University system is the zero-pay gap. Indeed, both male and female employees at Italian Universities have the same salary because it is regulated by law. In our knowledge, the Italian university system is unique in this - against salary gaps that can vary between $15 \%$ and $30 \%$ in European and North-America university systems (Hatch, 2017; Grove, 2015; Statistics Canada, 2018).

In conclusion, our suggestion is that the academic institution should not consider the gender gap as a specific issue related to academia, but rather a more general and common problem present in all work places, thus requiring tangible efforts to promote a welfare system that better reconciles family and work. More importantly a cultural change leading to a reorganization of the work system, still currently set on the male model, is needed, as well as an increase in the number of female top academics, who could act as mentors to a new generation of female researchers.

Data availability. All data discussed in this paper are available in the tables provided and they are also publicly accessible on the web through the official website cited in the text.

Author contributions. FN conceived the work. CA, FN, MGP, GS and $\mathrm{KB}$ carried it out. CA and FN prepared the manuscript with contributions from all co-authors.

Competing interests. The authors declare that they have no conflict of interest. 
Special issue statement. This article is part of the special issue "Diversity and equality in the geosciences (EGU2019 EOS6.1 \& US4, AGU2018 ED41B, JpGU2019 U-02)". It is a result of the EGU General Assembly 2019, Vienna, Austria, 7-12 April 2019.

Acknowledgements. Fabrizio Nestola, Claudia Agnini and Gabriella Salviulo were funded by DOR nos. 1945809/19 1978594/19 and 1920943/19 (Department of Geosciences, University of Padova). The authors would thank the reviewers and the editor for the thoughtful comments that have substantially improved the original version of the manuscript.

Financial support. This research has been supported by the European Research Council (grant no. 307322), the H2020 Marie Skłodowska-Curie Actions (grant no. SINDIA 796755) and the DOR fund of the University of Padova (Fabrizio Nestola - grant no. 1945809/19, Claudia Agnini - grant no. 1978594/19 and Gabriella Salviulo - grant no. 1920943/19.

Review statement. This paper was edited by Elena Toth and reviewed by Giovanna Galizzi and one anonymous referee.

\section{References}

Alma Laurea - Consorzio interuniversitario Almalaurea, available at: https://www.almalaurea.it/, last access: 28 November 2019.

Barone, C.: Some things never change: gender segregation in higher education across eight nations and three decades, Sociol. Educ., 84, 157-176, 2011.

Broome, J.: The Future of Geoscience in the 21st Century: Art, Science, or Resource?, in: The Current Role of Geological Mapping in Geosciences. NATO Science Series, Series IV: Earth and Environmental Sciences, vol. 56, edited by: Ostaficzuk, S. R., Springer, Dordrecht, 2005.

Burke, R. J. and Mattis, M. C.: Women and minorities in science, technology, engineering, and mathematics: Upping the numbers, Edward Elgar, Cheltenham, England, 2007.

Ceci, S. J. and Williams, W. M.: Understanding current causes of women's underrepresentation in science, P. Natl. Acad. Sci. USA, 108, 3157-3162, 2011.

Ceci, S. J., Williams, W. M., and Barnett, S. M.: Women's underrepresentation in science: Sociocultural and biological considerations, Psycholog. Bull., 135, 218-261, 2009.

Cheryan, S., Ziegler, S. A., Montoya, A. K., and Jiang, L.: Why are some STEM fields more gender balanced thanothers?, Psycholog. Bull., 143, 1-35, 2017.

DESTATIS: Statistisches Bundesamt, available at: https://www. destatis.de/DE/Home/_inhalt.html, last access: October 2019.

EIGE - European Institute for Gender Equality: Gender Segregation in Education, Training and the Labour Market: emerging Findings from the Beijing Platform for Action Report STEM Gender Equality Congress, European Parliament, 8-9 March, available at: https://eurogender.eige.europa.eu/system/files/ events-files/stem_gender_equality_congress_berlin.pdf (last access: 31 October 2019), 2017a.
EIGE - European Institute for Gender Equality: Gender equality index 2017, Measuring Gender Equality in the European Union 2005-2015, Publication office of the European Union, Luxembourg, available at: https://eige.europa.eu/publications/gender-equality-index-2017measuring-gender-equality (last access: 31 October 2019), $2017 b$.

European commission (Directorate-General for Research and Innovation): She figures 2006, Office for Official Publications of the European Communities, Luxembourg, 110 pp., ISBN 92-7901566-4, 2006.

European commission (Directorate-General for Research and Innovation): She figures handbook 2018, Office for Official Publications of the European Communities, Luxembourg, 214 pp., ISBN 978-92-79-86715-6, https://doi.org/10.2777/936, 2019.

EUROSTAT: EUROSTAT, available at: https://ec.europa.eu/ eurostat, last access: 28 November 2019.

Filandri, M. and Pasqua, S.: Being good isn't good enough: gender discrimination in Italian academia, Studies in Higher Education, https://doi.org/10.1080/03075079.2019.1693990, 2019.

Glass, J. N.: We are the 20\%: Updated Statistics on Female Faculty in Earth Sciences in the U.S., in: Female in the Geosciences: Practical, Positive Practices Toward Parity, edited by: Holmes, M. A., OConnell, S., and Dutt, K., John Wiley \& Sons, Inc., Washington, D.C., USA, 17-22, https://doi.org/10.1002/9781119067573, 2015.

Grove, J.: Times Higher Education Pay survey, available at: https://www.timeshighereducation.com/features/ times-higher-education-pay-survey-2015/2019360.article (last access: 31 October 2019), 2015.

Hassink, W. H. J. and Russo, G.: The Glass Door: The Gender Composition of Newly-Hired Workers Across Hierarchical Job Levels, IZA Discussion Paper 4858, Institute of Labor Economics (IZA), Bonn, Germany, 2010.

Hatch, J.: Gender Pay Gap Persists Across Faculty Ranks, Chronicle of Higher Education, available at: https://www.chronicle. com/article/Gender-Pay-Gap-PersistsAcross/239553 (last access: 31 October 2019), 2017.

Holmes, A.: Times Higher Education - Gender Pay Gap: Universities Are Doing Better than the BBC, available at: https://www. timeshighereducation.com (last access: 31 October 2019), 2017.

Holmes, M., O'Connell, S., Frey, C., and Ongley, L.: Gender imbalance in US geoscience academia, Nat. Geosci., 1, 79-82, https://doi.org/10.1038/ngeo113, 2008.

ISTAT - Istituto Nazionale di Statistica: ISTAT, available at: https: //www.istat.it/, last access: October 2019.

Macarie, F. C. and Moldovan, O.: Horizontal and vertical gender segregation in higher education: EU 28 under scrutiny, Manage. Challen. Contemp. Soc., 8, 162-169, 2015.

MIUR - Italian Ministry of School, University and Research: MIUR, available at: https://cercauniversita.cineca.it/ php5/docenti/cerca.php, last access: October 2019.

Pautasso, M.: The Italian University Habilitation and the Challenge of Increasing the Representation of Women in Academia, Challenges, 6, 26-41, 2015.

Roberto, F., Rey, A., Maglio, R., and Agliata, F.: The academic "glass-ceiling": investigating the increase of female academicians in Italy, Int. J. Organiz. Anal., https://doi.org/10.1108/IJOA-06-2019-1779, 2020. 
Sattari, N. and Sandefur, R. L.: Gender in academic STEM: a focus on men faculty, Gender Work Organiz., 26, 158-179, 2019.

Statistics Canada: Statistics Canada, available at: https://www150. statcan.gc.ca/t1/tbl1/en/tv.action?pid=3710010801 (last access: 31 Ocotber 2019), 2018.
Wilson, C.: Status of the Geoscience Workforce 2016, American Geosciences Institute, p. 140, available at: https://www.americangeosciences.org/citations/ status-geoscience-workforce-2016 (last access: 31 October 2019), 2016. 